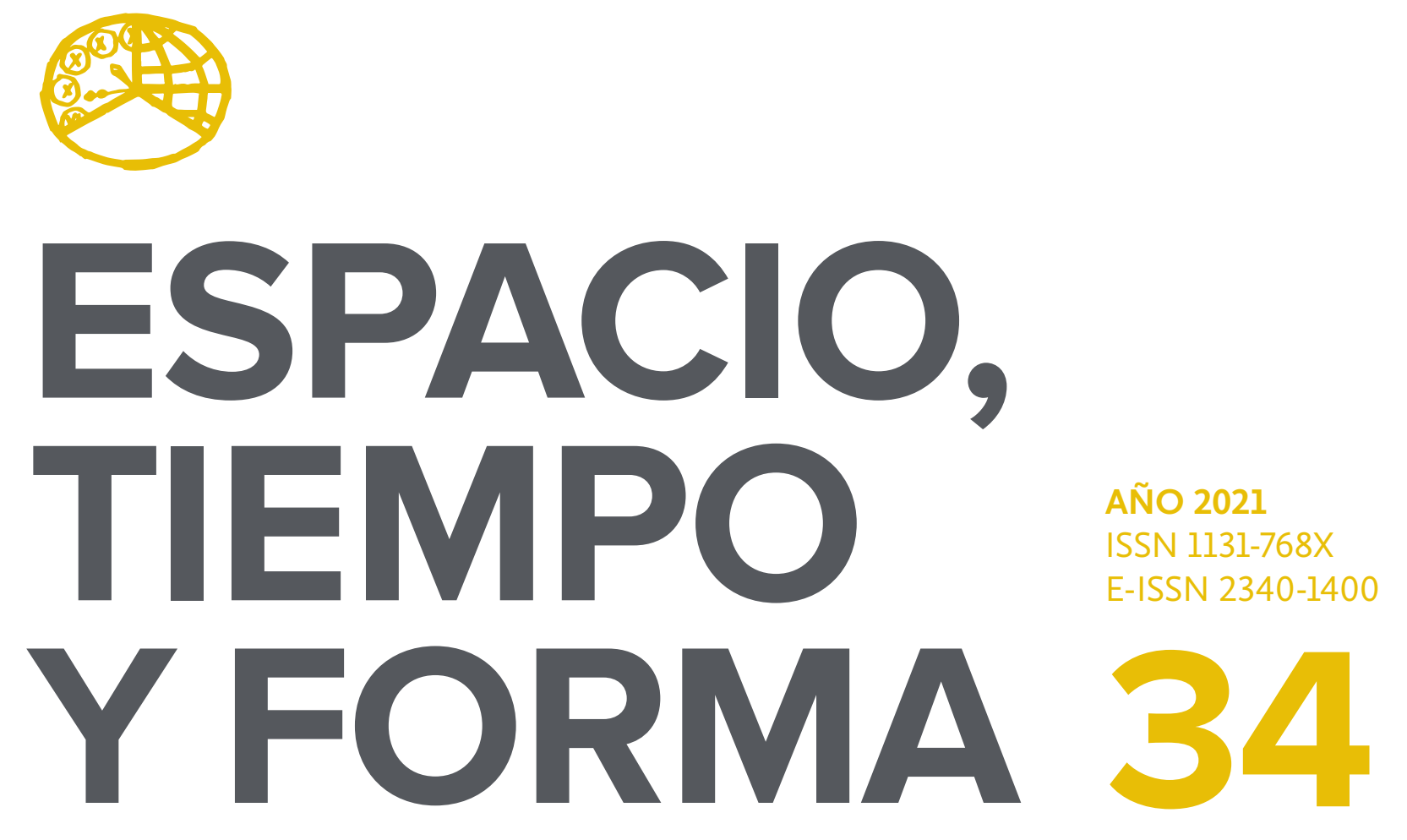

SERIE IV HISTORIA MODERNA

REVISTA DE LA FACULTAD DE GEOGRAFÍA E HISTORIA

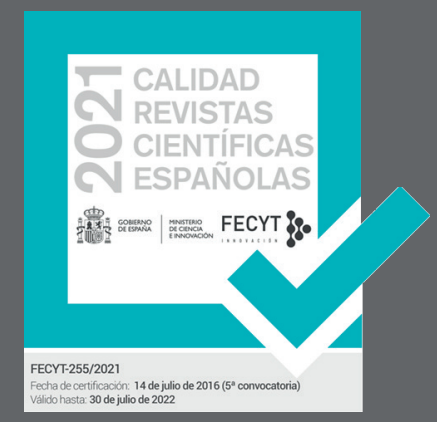




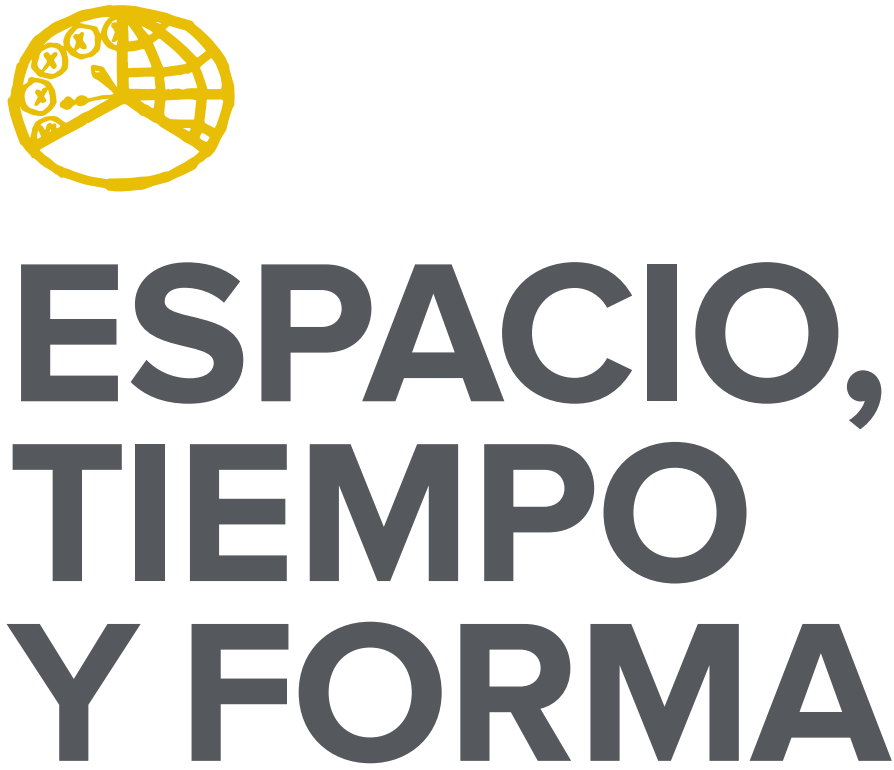

AÑO 2021

ISSN 1131-768X

E-ISSN 2340-1400

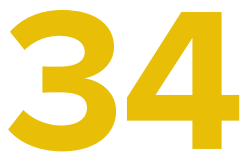

SERIE IV HISTORIA MODERNA

REVISTA DE LA FACULTAD DE GEOGRAFÍA E HISTORIA

DOI: https://doi.org/10.5944/etfiv.34.2021

\section{UกED}

UNIVERSIDAD NACIONAL DE EDUCACIÓN A DISTANCIA 
La revista Espacio, Tiempo y Forma (siglas recomendadas: ETF), de la Facultad de Geografía e Historia de la UNED, que inició su publicación el año 1988, está organizada de la siguiente forma:

$$
\begin{aligned}
& \text { SERIE I - Prehistoria y Arqueología } \\
& \text { SERIE II - Historia Antigua } \\
& \text { SERIE III - Historia Medieval } \\
& \text { SERIE IV - Historia Moderna } \\
& \text { SERIE V - Historia Contemporánea } \\
& \text { SERIE VI - Geografía } \\
& \text { SERIE VII - Historia del Arte }
\end{aligned}
$$

Excepcionalmente, algunos volúmenes del año 1988 atienden a la siguiente numeración:

$$
\begin{aligned}
& \mathrm{N} .^{\circ} 1 \text { - Historia Contemporánea } \\
& \mathrm{N}^{\circ} 2 \text { - Historia del Arte } \\
& \mathrm{N} .^{\circ} 3 \text { - Geografía } \\
& \mathrm{N} .^{\circ} 4 \text { - Historia Moderna }
\end{aligned}
$$

ETF no se solidariza necesariamente con las opiniones expresadas por los autores.

\author{
UNIVERSIDAD NACIONAL DE EDUCACIÓN A DISTANCIA \\ Madrid, 2021 \\ SERIE IV · HISTORIA MODERNA N. ${ }^{\circ} 34,2021$ \\ ISSN $1131-768 X \cdot$ E-ISSN 2340-1400 \\ DEPÓSITO LEGAL \\ M-21.037-1988 \\ URL \\ ETF IV · HISTORIA MODERNA · http://revistas.uned.es/index.php/ETFIV \\ DISEÑO Y COMPOSICIÓN \\ Carmen Chincoa Gallardo · http://www.laurisilva.net/cch \\ Impreso en España · Printed in Spain
}

(c) (7) (8) Esta obra está bajo una licencia Creative Commons Reconocimiento-NoComercial 4.0 Internacional. 


\section{MONOGRÁFICO · SPECIAL ISSUE}

LA POLÍTICA ULTRAMARINA DE LAS MONARQUÍAS

IBÉRICAS (CIRCA 1700-1750): UNA HISTORIA

DE FRACASOS Y ÉXITOS RELATIVOS

THE OVERSEAS POLICY OF THE IBERIAN MONARCHIES (CIRCA 1700-1750): A HISTORY OF FAILURES AND RELATIVE SUCCESSES 



\title{
ECOS DE UN MERCANTILISMO TRUNCADO. EL CONDE DE PINOS PUENTE Y LA DIPLOMACIA COMERCIAL DE CARLOS VI EN LA CORTE DE LISBOA (1723-1724)
}

\author{
ECHOES OF A FAILED MERCANTILISM. \\ THE COUNT OF PINOS PUENTE AND THE \\ COMMERCIAL DIPLOMACY OF CHARLES VI \\ AT THE COURT OF LISBON (1723-1724)
}

\author{
Roberto Quirós Rosado \\ Recibido: 15/12/2020 - Aceptado: 22/04/2021 \\ DOI: https://doi.org/10.5944/etfiv.34.2021.29358
}

\begin{abstract}
Resumen ${ }^{2}$
Las consecuencias de la guerra de Sucesión española alejaron del Nuevo Mundo al emperador Carlos VI de Habsburgo. Tras los intentos infructuosos para movilizar redes políticas en los reinos de Indias, el Austria proyectó su poder al mundo ultramarino, no con una intervención armada directa, sino con la articulación de la Compañía de Ostende y la Privilegiada Compañía Oriental Imperial, con sedes en Viena y Trieste. A causa de la emulación de Gran Bretaña, las Provincias Unidas y las Dos Coronas borbónicas, el emperador remitió en I723 un enviado extraordinario a Lisboa para lograr la cobertura de Juan V de Portugal a dichas empresas: Juan Jacinto Vázquez de Vargas, conde de Pinos Puente. A través de su misión -fracasada o pírrica- se conocerán los medios de negociación con las autoridades lusas, la rearticulación de redes comerciales regio-cesáreas imbricadas en las lógicas del comercio ultramarino luso y el impacto de las prácticas informales de la diplomacia a la hora de captar voluntades para los intereses de Carlos VI.
\end{abstract}

1. Universidad Autónoma de Madrid; roberto.quiros@uam.es

2. Este estudio forma parte del proyecto europeo «FAILURE: Reversing the Genealogies of Unsuccess, 16th19th Centuries» [H2020-MSCA-RISE, Grant agreement: 823998], dentro de las líneas de trabajo establecidas en el WP4 «Unsuccessful polities, from empire to nations, and international relationships», y se ha desarrollado en el marco del proyecto Práctica de gobierno y cultura política: Europa y América en la monarquía de España, 1668-1725 [PID2019-108822GB-loo], concedido por el Ministerio de Ciencia e Innovación.

Abreviaturas utilizadas: Archivo General Militar de Madrid (AGMM, Madrid), Archivo General de Simancas (AGS, Simancas), Archivo Histórico Nacional (AHN, Madrid), Archivio di Stato di Napoli (ASN, Nápoles), Haus-, Hof- und Staatsarchiv (HHStA, Viena). 
Palabras clave

Mercantilismo. Carlos VI de Habsburgo; Juan V de Portugal; Compañía de Ostende; Privilegiada Compañía Oriental Imperial

\section{Abstract}

The geopolitical consequences of the War of the Spanish Succession drove away from the New World the Habsburg Emperor Charles Vl. After unsuccessful attempts to mobilise political networks in the Kingdoms of the Indies, the Habsburg projected its power to the overseas, not through direct armed intervention, but through the articulation of the Company of Ostend and the Imperial Privileged Oriental Company, settled in Vienna and Trieste. Because of the emulation of Great Britain, the United Provinces and the two Bourbon Crowns of France and Spain, the Emperor sent an extraordinary envoy to Lisbon in 1723 to achieve the cover of John V of Portugal for these companies: Juan Jacinto Vázquez de Vargas, Count of Pinos Puente. Through his mission - whether unsuccessful or pyrrhic - it is possible to learn about the means of negotiating with the court the Bragança sovereign, the re-articulation of the Imperial commercial networks that are part of the logic of Portuguese overseas trade, and the impact of informal diplomatic practices of the ministers of Charles VI.

\section{Keywords}

Mercantilism; Charles VI of Habsburg; John V of Portugal; Ostend Company; Imperial Privileged Oriental Company 


\section{A MODO DE INTRODUCCIÓN: UN GRANADINO EN EL EPISTOLARIO METASTASIO-FARINELLI}

El 6 de agosto de I749, desde Viena, Pietro Antonio Domenico Bonaventura Trapassi, conocido en toda Europa como Metastasio, cerraba de una manera extraordinaria una misiva a su corresponsal y amigo Farinelli, el castrato napolitano Carlo Broschi: «Voi credete ch'io abbia finito! Signor no. La coda è sempre la più dura a scorticare. Attento». Las palabras que seguían al scherzo del dramaturgo romano contenían una extraña petición recibida del anciano General-Feldmarschall Juan Jacinto Vázquez de Vargas, conde de Pinos Puente. El aristócrata, natural de Granada, aducía haber admirado su obra en casa de su suegro, el marqués de Rialp, cuando este ejercía como secretario del Despacho Universal de Carlos Vl, y ahora recurría a Metastasio para lograr su ayuda. El objetivo de su petición se fundaba en la necesidad de captar a Broschi para que mediase en beneficio de un sobrino del peticionario, Juan Jacinto Varáez y Vázquez, chantre de Zamora, quien, aunque tenía firmes apoyos en la corte de Portugal, no eran similares a los que le permitirían acceder a la reina de España, Bárbara de Braganza. Sin duda alguna, Pinos Puente era bien conocido en la Lisboa de Juan $\mathrm{V}$ y por la propia soberana hispana «quando questo cavaliere vi fu inviato dall'imperatore Carlo VI», pero dicha solicitud escondía la soledad de su linaje en la borbónica Madrid. Recurrir al castrato, valido de Fernando $\mathrm{VI}$ y de su esposa, era fundamental para el éxito del intento, si bien el propio Metastasio consideraba el asunto como un negocio sin mayor interés para su persona. «Per altro io non conosco il nipote, e non devo cosa alcuna al zio», sentenciaba el poeta, aunque adujo que el conde podría ayudarle en algunos empeños vieneses. Teniendo en cuenta la amistad entre ambos honnêtes hommes, el asunto podía zanjarse con una carta de cortesía de Farinelli para mostrar a Pinos Puente y un tratamiento gentil del cantante al portador de la recomendación, «affinché se non potete essere utile a lui, lo siate almeno a me, facendo conoscere che siete il mio gemello e che mi amate a proporzione di questo tenero nome».

\section{¿UNA MISIÓN DESTINADA AL FRACASO? EL MERCANTILISMO HABSBÚRGICO Y LA ESTANCIA LISBOETA DEL CONDE DE PINOS PUENTE}

La mediación metastasiana a favor de un oscuro clérigo andaluz trasciende su consideración cual pequeño episodio en la relación fraterna entre el dramaturgo y el músico. La figura de Juan Jacinto Vázquez de Vargas (Granada, I68I-Viena, I754), primer conde de Pinos Puente, emerge en la precedente misiva dentro de un contexto austro-portugués que, en I749, solo recordaría un conspicuo núcleo de fidalgos y cortesanos lusos que coincidieron años atrás con el aristócrata en una misión diplomático-mercantil. La conciencia de Metastasio de que las pretensiones

3. Cartas de Metastasio a Farinelli, Viena, 6 de agosto de 1749, cfr. CARDucCI, 1883: 277-280. 
de Pinos Puente «saranno validamente secondate dalla corte di Lisboa», o que Farinelli pudiese «far sovvenire alla real cattolica maestà della vostra adorabile sovrana [Bárbara de Braganza] il tempo in cui il signor maresciallo conte di Pinos ebbe l'onore di farle la sua corte in Portogallo», serían muestra de ello4.

La positiva memoria del militar y diplomático andaluz en la corte portuguesa ocultaba el ambiguo tratamiento que recibió durante el curso de las negociaciones que desplegó, durante más de once meses, a caballo de I723 y I724 en nombre de Carlos VI de Habsburgo y en pro de las dos compañías que dicho rey-emperador había privilegiado poco tiempo atrás: la Compañía de Ostende y la Privilegiada Compañía Oriental Imperial, radicada en Viena y Trieste ${ }^{5}$. Tras el fracaso de los intentos de capitalizar redes ultramarinas capaces de devolver los reinos de Indias al todavía Carlos IIl y su monarquía de España de Oriente durante la guerra de Sucesión española, estas dos corporaciones surgieron como consecuencia del reforzamiento del poder europeo de la Casa de Austria tras las paces de Utrecht, Rastatt y Baden ${ }^{6}$. Mientras que la declaración de Fiume y Trieste como puertos francos en I7I9 coincidió con la creación de un consorcio destinado a promover los lazos mercantiles en el Adriático imperial aprovechando los vínculos entre dichas urbes y los puertos del reino de Nápoles, la Compañía de Ostende hundía sus raíces a un lustro atrás. Gracias a la promoción del comercio del puerto flamenco por parte del irlandés Thomas Ray, numerosos hombres de negocios de los Países Bajos que acababan de reconocer -tras la ocupación aliada- la soberanía carolina se dispusieron a ampliar el radio de exportación de sus manufacturas con la creación de emporios orientales en India, China e, incluso, Arabia. Paulatinamente, inversores de distintas naciones, desde flamencos hasta británicos, pasando por franceses, neerlandeses o austriacos, destinaron capitales y productos al pingüe tráfico establecido desde Ostende hasta el océano Índico, mientras que el curso del río Danubio, el mar Adriático y el Mediterráneo verían surcar barcos de la Compañía Oriental cesárea. El director de dicho lobby mercantil, conde Philipp Ludwig Wenzel von Sinzendorf -también Obershofkanzler desde I705-, amparó la creación de almacenes y factorías triestinas en las principales urbes habsbúrgicas de los Balcanes y el Mediterráneo central, y proyectó el establecimiento de canales alternativos de atracción de caudales, caso de inyecciones de liquidez provenientes de los banqueros cortesanos o la creación puntual de sorteos de lotería que sufragasen las incipientes deudas del consorcio.

A la altura de 1723 , el florecimiento general de ambas compañías privilegiadas motivó la apertura hacia nuevos mercados y socios, esta vez contando con el soporte de acuerdos diplomáticos que posibilitasen su reconocimiento internacional y limitasen, por esta vía, el rechazo de potencias tradicionalmente ligadas al comercio ultramarino (Gran Bretaña, Provincias Unidas, Francia y la España borbónica) que

4. Ibidem.

5. Para una panorámica general sobre ambas compañías, cabe destacar las obras de FABER, 1994; WANNER, 2006; WANNER, 2007; ANDREOZZI, 2015; y DREIJER, 2017.

6. Sobre la articulación política de la monarquía de España oriental de los Habsburgo, tanto en sus cortes de Valencia, Barcelona y Viena como en sus provincias italianas, durante la guerra sucesoria, vid. QUIRós RoSADO, 2017. 
aprovecharon para este fin la Conferencia de Cambrai (I72I-I724)7. Conociendo la imposibilidad de que ninguna de las coronas y repúblicas mercantilistas apoyaran de manera abierta la inclusión de la monarquía habsbúrgica en el concierto económico atlántico o índico, el emperador Carlos VI decidió dirigir una misión ad hoc a Portugal para lograr la firma de un acuerdo que franquease los puertos del Estado da Índia a los navíos ostendeses y que permitiese el amparo de los navíos de la Compañía triestina en la rada y los almacenes de Lisboa.

La persona elegida para negociar tales materias en la corte portuguesa atesoraba casi tres lustros de servicio al rey-emperador. Juan Jacinto Vázquez de Vargas había nacido en el seno de una familia de la pequeña nobleza andaluza. Nieto, por vía paterna, del veinticuatro granadino Juan Jacinto Vázquez y Villarreal, por la materna era descendiente del advenedizo toledano Francisco Simón de Vargas, que había adquirido otra veinticuatría de Granada a mediados del siglo XVII. Antonio Vázquez Cano, padre del futuro conde de Pinos Puente, debía su riqueza no tanto a su progenitor, sino a su madre Isabel Cano del Salto, oriunda de Pinos Puente. Por su parte, don Antonio accedió al oficio concejil en i674 y lo retuvo hasta su muerte en I734. Su matrimonio con Francisca de Vargas no solo posibilitó la sucesión de un hijo varón -el futuro conde- en el vínculo de los Vázquez, sino la concepción de dos hijas que casarían con sujetos bien situados en su ciudad natal: doña Francisca con Rodrigo de Valdivia, y doña María Alfonsa con Pedro Varáez, veinticuatro y caballero de Calatrava ${ }^{8}$.

Contando con un amplio soporte relacional y económico en el reino de Granada, el joven Juan Jacinto Vázquez de Vargas pronto accedió al servicio a Felipe V. En I702, este veinticuatro iliberritano fungió la comandancia del segundo batallón de caballería de Granada durante las levas tendentes a reforzar el reino de Sevilla ante la invasión anglo-neerlandesa del golfo de Cádiz. Estos méritos posibilitaron la concesión de un hábito de la Orden de Santiago en I703, validado por el Consejo de Órdenes en la siguiente primavera e impuesto por el marqués de Santa Cruz en Madrid a fines de $1706^{9}$. Tras verse afectado por la reforma de dichos cuerpos segundos en plena contraofensiva sobre Gibraltar, en septiembre de 1705 obtuvo de los consejeros de Guerra un parecer favorable para conseguir una compañía de caballería, aunque esta no se materializó hasta el año siguiente. En una nueva coyuntura crítica para los intereses del monarca Borbón, con la primera conquista aliada de Madrid en el verano de I706, el segundo batallón granadino se convertiría al pie regimental y su titular, Vázquez de Vargas, se hizo con el grado de coronel, siempre y cuando lograse reclutar toda su planta en su ciudad natal. En poco tiempo,

7. Frente a los mejor conocidos congresos de paz de 1713-1715, son todavía desconocidos gran parte de los pormenores del congreso de Cambrai. Una reciente aproximación a este encuentro diplomático se corresponde con DHONDT, 2013.

8. Marina Barba, 1992: 76-77; Martínez Fernández, 1998: 162.

9. AHN, Órdenes Militares. Caballeros de Santiago, expediente 8595. Genealogía de Juan Jacinto Vázquez de Vargas, Madrid, 6 de diciembre de 1703, y auto de aprobación del Consejo de Órdenes de las pruebas realizadas sobre su linaje, Madrid, 29 de abril de 1704. AHN, Órdenes Militares. Expedientillos, número 16830. Registro del testimonio de cómo se armó cavallero de la Orden de Santiago y se dio el ábito e insignia de ella a don Juan Jazinto Bázquez de Bargas, Convento de San Bernardo de Madrid, 12 de diciembre de 1706. 
el regimiento de Granada alcanzó la cifra de quinientos hombres y fue encaminado a la defensa del reino de Murcia. Sería solamente el i6 de enero de I707 cuando don Juan Jacinto alcanzó el rango efectivo de coronel ${ }^{10}$.

La incuestionable fidelidad borbónica de Juan Jacinto Vázquez de Vargas mutó sorpresivamente cuando se pasó a las filas de Carlos III de Austria a la cabeza de su regimiento mientras se encontraba, de nuevo, frente a la plaza de Gibraltar. Ya en la corte de Barcelona, el militar granadino fue agraciado con el «título de conde del lugar de Pinos de la Puente» el 24 de septiembre de i7II. Aunque solo se tiene constancia documental de que pagase por este hereditario título de Castilla la caución de la media anata de 562.000 maravedís, tal y como atestigua el privilegio de la emperatriz Isabel Cristina de Braunschweig-Wolfenbüttel de 30 de diciembre de I7I2, el contexto de la concesión -en vísperas de la partida del monarca Habsburgo hacia Italia y el Sacro Imperio para ceñir la corona imperial- permite presuponer que hubiese una operación venal que coadyuvara, como en otros casos paralelos, a la financiación del periplo real ${ }^{\mathrm{II}}$.

La estancia del conde de Pinos Puente en Cataluña culminó con motivo del convenio de Hospitalet (22 de junio de I713), dirigiéndose junto a sus hombres a tierras cesáreas, donde don Juan Jacinto volvería a escenarios de guerra viva. La vacante del regimiento del teniente general Pedro Morrás y Mauleón, marqués de Honrubia, en I7i6 fue cubierta en la persona de Vázquez de Vargas, ya graduado como general. Como tal coronel propietario, el conde ejerció el mando de este reputado cuerpo de caballería durante la guerra Austro-Turca de i716-1718, tanto en Hungría como en Serbia, valiéndose de Luis Arroyo como coronel gobernador y de Felip Vilana i Millàs como teniente coronel $^{12}$. El vínculo clientelar de Pinos Puente con los Vilana no era baladí. Tras asentarse en la urbe austriaca, don Juan Jacinto había desposado en I7I4 a Maria Ignàsia Vilana Perles, la hija de Ramon Frederic de Vilana Perles, marqués de Rialp y secretario del Despacho Universal en el Consejo Supremo de España, el más poderoso ministro español de Carlos $\mathrm{VI}^{13}$. De su unión matrimonial solo tendría un hijo varón, Antonio Vázquez y Vilana Perles, pero tan ventajoso enlace permitió al conde reforzar su progresión sociopolítica y afianzarse como propietario y benefactor de obras pías en el archiducado de Austria. Suegro y yerno adquirirían en i722 el Thurnhof de Brunn am Gebirge, población en la que los condes de Pinos Puente habían pasado varias jornadas veraniegas y en donde, de hecho, falleció doña Maria

10. AGMM, Libros Registro, libro 71, f. 3or. Regesto de consulta del Consejo de Guerra, Madrid, 5 de septiembre de 1705; libro 74, ff. 107r-108r. Privilegio de Felipe V a favor de Juan Francisco Vázquez de Vargas, Madrid, 16 de enero de 1707. Sobre el regimiento de caballería de Granada y la guerra de Sucesión española, véase SotTO, 1856: $321-322$.

11. AHN, Estado, legajo 8695. Relación de concesiones de Carlos III a distintos particulares en septiembre de 1711, Sin lugar, ni fecha. ASN, Consiglio di Spagna, vol. 58, ff. 229r-233r. Privilegios de Isabel Cristina de Braunschweig-Wolfenbüttel a favor de Juan Jacinto Vázquez de Vargas, Barcelona, 30 de diciembre de 1712. Sobre la coyuntura de concesiones de privilegios previos a la partida de Carlos III a Italia y el Sacro Imperio, vid. QuIRós RosADO, 2016: 128-129.

12. Nombres de los officiales españoles, desde general a alferes inclusive con exercicio de los 5 regimientos de españoles que sirvieron en la Ungría en la guerra contra el Turco en los años 1716 y 1717 y de los officiales agregados a otros regimientos, Sin lugar, ni año, cfr. AlcoberRo, 2002: 392.

13. La relevancia política de Rialp durante el reinado de Carlos III/VI aparece registrada en LLUCH, 2000 y LEÓN SANZ, 2014. 
Ignàsia (I72I). Como consecuencia del entierro de la señora en la parroquia local de St. Kunigunde, los Vázquez-Vilana Perles asumieron el patronato de la iglesia y, en colaboración con el infante portugués Manuel de Braganza, reformaron integralmente su interior y exterior en una obra que culminó en $1732^{14}$.

La elevada posición de Juan Jacinto Vázquez de Vargas en las esferas de poder de Viena, en tanto militar de prestigio y hechura familiar de Rialp, le permitieron ser elegido como enviado extraordinario a la corte de Lisboa para obtener cuantiosos acuerdos mercantiles para las dos compañías privilegiadas del emperador. A mediados de I723, los lazos entre Carlos VI y Juan V de Portugal distaban de una cercanía política palpable. Si bien los vínculos parentelares les convertían en primos hermanos por sus vías maternas en tanto descendientes de los duques del PalatinadoNeoburgo, con el matrimonio del Braganza -en I708- con la archiduquesa María Ana de Habsburgo, la afinidad de los lazos de sangre les hacía hermanos. No obstante, la continuidad de representantes diplomáticos habsbúrgicos en Lisboa se había roto hacía varios años. En plena guerra de Sucesión, el todavía Carlos III remitió al conde Uberto Stampa como embajador extraordinario (I709) y utilizó al jesuita Álvaro Cienfuegos como agente informal y plenipotenciario ${ }^{15}$. Tras el fin del conflicto en la península Ibérica, la disparidad de horizontes políticos y económicos entre las cortes de Lisboa y Viena redujo los intereses comunes a la existencia de un cónsul y un agente cesáreos en la primera, a meras cortesías epistolares y al mantenimiento del mencionado -y conflictivo- infante Manuel de Braganza como huésped del césar Carlos en tierras centroeuropeas de $17 \mathrm{I} 6$ a $1734^{16}$.

Investido con el oficio de capitán de la compañía de Guardias de Sicilia, reino en el que ya disfrutaba la encomienda santiaguista de San Calogero, el conde de Pinos Puente preparó su marcha durante el mes de junio ${ }^{17}$. Aunque la comisión que portaba a Portugal era secreta, pronto los canales diplomáticos lusos avisaron de sus encargos. El agente oficioso de Juan $\mathrm{V}$ en la corte imperial dio cuenta al embajador en París, Luís da Cunha, cómo el andaluz quedaba encomendado para

«representar a El-Rey nosso senhor o quanto dezeja que Sua Magestade restetua a sua real graça o senhor Infante, e além desta propozição se ajuste também a da abertura do Comércio de Trieste, que permita a Deos tenha bom suçesso tanto em hua couza como na outra» ${ }^{18}$.

La resolución del affaire de dom Manuel, que había lastrado la cordialidad entre ambas cortes desde hacía más de un lustro, no era el núcleo de la misión de Pinos Puente. La negociación de privilegios mercantiles que consolidasen las rutas ultramarinas de las compañías privilegiadas que el emperador había aprobado en

14. COSTA TROSt, 2016: 279-280.

15. SILVA, 1750: 302

16. Sobre la disyuntiva política de Portugal ante la guerra de Sucesión española, véase MARTín MARCOS, 2014. La única semblanza existente en torno al infante se debe a SOARES, 1937.

17. Le Mercure de juillet 1723, 1723: s. p. Avisos, Viena, julio de 1723.

18. Carta del agente Barbosa a Luís da Cunha, Brunn, 24 de junio de 1723, cfr. Alves MiRanda, 2002: 259. 
Viena-Trieste y Ostende sí ejercería de verdadera razón del viaje de un aristócrata que, pese a su largo servicio con las armas a la Casa de Austria, no había llevado a cabo ninguna labor diplomática previa.

El viaje a Lisboa tuvo escalas intermedias en La Haya y Londres, desde donde partió a fines de agosto en el paquebote británico The Expedition ${ }^{\mathrm{I}}$. A tenor de los testimonios de sus coetáneos, el nombramiento de un nuevo enviado extraordinario a la corte portuguesa suscitó una inusitada atención de los medios informativos de toda Europa. Desde Il foglio di Foligno hasta The London Gazette, la opinión pública pudo conocer sus pasos y comisiones. Por ejemplo, la gaceta italiana no dudó en hacerse eco de las noticias lisboetas que hablaban cómo entre ambas potencias «si trattava sotto mano lo stabilimento di una compagnia in Affrica toccante il commercio de' schiavi $»^{20}$, mientras que la londinense apuntó a sus lectores una semblanza del enviado regio-cesáreo:

«He is a Spanish Nobleman, who followed the Emperour's Party in the late War, was created Conde by his Imperial Majesty, when at Barcelona, and has now a Regiment of Horse in his Service» ${ }^{21}$.

Por su parte, en la misma corte lusa corrían voces sobre la llegada del conde, que tuvo lugar el 8 de septiembre. Dos días antes, Pedro António de Noronha, marqués de Angeja, escribía sus impresiones ante el inminente arribo a su corresponsal en París, Marco António de Azevedo Coutinho, en particular «se assim he supponho virá a dar os parabéns a El-Rey nosso senhor pelo Infante [Alejandro de Braganza], que esperamos em Deos nos dará neste mez» ${ }^{22}$. El trasunto dinástico que podía esconder la misión, para Angeja, no debía estar desencaminado. La estrecha relación entre Pinos Puente y dom Manuel no era un secreto. En Lisboa se conocía la confianza depositada por el Braganza en el enviado carolino, establecida durante la guerra contra los otomanos y reforzada durante el viaje del infante a Reims para asistir a la coronación de Luis XV, en octubre de I722. Sin embargo, los avisos que circulaban en el mentidero del Chafariz de El-Rei tardaron en recoger sus intenciones reales que, curiosamente, sí propugnaban los medios impresos europeos ${ }^{23}$.

Si bien Pinos Puente mantuvo la primera audiencia con Juan V el io de septiembre, durante varias semanas su misión estuvo marcada por la disimulación y no dejó de bascular entre secretos y medias verdades. Solo con la llegada, a mediados de octubre, de dos navíos de guerra napolitanos y tres barcos de la Compañía Oriental de Trieste, el avisado marqués de Angeja pudo conjeturar

19. CORREIA, 1965: 23-24.

20. Foglio di Foligno, $\mathrm{n}^{\circ}$ 38, 1723: s. p. Avisos de La Haya, 11 de agosto de 1723.

21. The London Gazette, $\mathrm{n}^{\circ} 6203$, 1723: s. p. Avisos de Lisboa, 20 de septiembre de 1723.

22. Carta del marqués de Angeja a Marco António de Azevedo Coutinho, Lisboa, 6 de septiembre de 1723, cfr. AzEVEDO, 1918: 1000.

23. Carta del marqués de Angeja a Marco António de Azevedo Coutinho, Lisboa, 20 de septiembre de 1723, cfr. AZEVEDO, 1918: 1001. 
con más evidencias los intereses que habían encaminado al conde a Lisboa ${ }^{24}$. El surgimiento de este lobby privilegiado por el emperador entre Viena y el puerto adriático no parecía tan lucrativo para sus accionistas como sí lo era el que mostraban los de la Compañía de Ostende desde hacía varios años,

«que com rezam se fazem tam ciozos aos olandezes pelos interesses serem muy próximos, e os de Itália para Portugal muy remotos, a quem só com demaziada speculação pode fazer algum prejuizo aos amburguezes» ${ }^{25}$.

La potencial introducción de los comerciantes de Viena-Trieste en el hinterland mercantil luso, a imagen y semejanza de lo que sus colegas flamencos habían tratado de proyectar, pese a la emulación de británicos y neerlandeses, «poderá bem ser verdade, e também mentira», a ojos de Angeja ${ }^{26}$. Pronto los cortesanos y opinadores saldrían de dudas. Contando con el canal privilegiado del influyente secretario de Estado, Diogo de Mendonça Corte Real, hombre de total confianza de Juan V y pieza central en el engranaje ministerial de $\operatorname{Lisboa}^{27}$ : el conde de Pinos Puente puso sobre su mesa las propuestas de máximos de Carlos Vl: un tratado de comercio que beneficiase a las dos compañías comerciales bajo su amparo. Este acuerdo llevaría consigo el soporte portugués a los navíos y convoyes flamencos e italianos tanto en las costas de Guinea, Angola y el Estado da Índia en las idas desde Europa, como en Brasil y el mismo Portugal durante su tornaviaje. Otra de las condiciones que el enviado plantearía al plumista luso fue la conversión de Goa como puerto franco para los barcos de bandera imperial. Asimismo, se proponía franquear la libre distribución entre las jurisdicciones y feitorias portuguesas de productos centroeuropeos, napolitanos y sicilianos - plata, cobre, plomo, azogue, lino y sedas- centralizados por los directores de la Compañía Oriental ${ }^{28}$.

Pasada la Navidad de I723, festividad que coincidió con la partida de los navíos de guerra napolitanos que habían llegado convoyando a los mercantes triestinos, el conde de Pinos Puente retomó el negociado con los ministros portugueses. El 2 de enero se encontró con Diogo de Mendonça Corte Real en la quinta que este poseía a las afueras de Lisboa. Pese a las presiones del diplomático, dom Diogo prosiguió difiriendo la resolución del asunto - «como a quatro meses que me dise esto mismo», a decir del granadino- y evitando unas palabras positivas que permitiesen a la Compañía de Trieste tomar sus disposiciones mercantiles. Las medidas contemporizadoras de los hombres de Juan $\mathrm{V}$ exasperaban al conde. En su correspondencia

\footnotetext{
24. Carta del marqués de Angeja a Marco António de Azevedo Coutinho, Lisboa, 19 de octubre de 1723, cfr. AZEVEDO, 1918: 1003

25. Ibidem.

26. Ibidem.

27. Sobre la influencia creciente del secretario de Estado lisboeta, en detrimento de órganos consiliarios como el Conselho Ultramarino, vid. BicalHo y COSTA, 2017, así como el texto de la propia Maria Fernanda Bicalho en el presente dossier de Espacio, Tiempo y Forma. Serie IV, Historia Moderna.

28. Entre las numerosas referencias que las gacetas europeas dieron sobre los objetivos -reales o ficticios- de la misión de Pinos Puente, cabe referir la referida en La clef du cabinet des princes de l'Europe, tomo XL, 1724: 19. Avisos de Lisboa, enero de 1724; o la inserta en Lettres historiques, tomo LXIV, 1723: 491. Avisos de Amberes, noviembre de 1723.
} 
con el canciller y director de la compañía triestina Philipp Ludwig Wenzel von Sinzendorf, Pinos Puente se sinceró afirmando cómo «beo la lentitud con que aquí se camina, no me es fásil poder dar punto fijo a nada» de los encargos que el propio ministro austriaco le había informado en persona, tanto en Praga -en vísperas de la coronación de Carlos VI como rey de Bohemia- como en Viena ${ }^{29}$.

Uno de los motivos de las dilaciones lisboetas podía provenir de un proyecto que, en paralelo al negociado habsbúrgico, se estaba debatiendo en el Paço da Ribeira. Se trataba de una compañía para África que, siguiendo los modelos de la extinta Companhia Real da Guiné de fines del siglo XVII, contaría con el apoyo del monarca. Esta fundación no era un secreto para ninguno de los diplomáticos radicados en la corte portuguesa. Así, el cónsul cesáreo Giuseppe Zignoni remitió noticias a Viena sobre dicha corporación, dando cuenta de las dificultades surgidas por los mercaderes que la dirigirían y los medios de participación en la misma ${ }^{30}$. Poco después fue la Gazeta de Lisboa Occidental la que anunciara el asenso regio a la Companhia para a costa de África. En el número tercero de 1724 se adujo públicamente el motivo de su instauración: la obtención de un mayor número de esclavos «para servirem nas lavouras do assucar e tabaco, e no trabalho das minas». El capitán francés Jean Dansaint y sus socios lusos Manoel Domingues do Paço, Francisco Nunes da Cruz y Lourenço Pereira y galos Noé de L'Houssaye y Barthélemy-Michel Vienne, acordaron con el monarca el reforzamiento de las factorías portuguesas en la costa guineana, con epicentro en la isla de Corisco, para proporcionar mano cautiva al floreciente Estado del Brasil ${ }^{3 \text {. }}$.

Otra de las causas del bloqueo al tratado de comercio luso-imperial en ciernes provenía de la ausencia que Rodrigo Anes de Sá, marqués de Abrantes, hacía de Lisboa, siendo uno de los señores que conformarían la junta destinada a «terminar este negosio» $3^{2}$. A la altura del il de enero de I724, Pinos Puente confesaba a Sinzendorf cómo no era aparente una resolución favorable hasta pasadas la sucesiva Semana Santa. La inactividad consumía al enviado:

«Lo cierto es que aquí no ai despacho en nada, pues sus flotas, que es lo que más les importa, debieron salir de aquí por el mes de disienbre i se mantienen sin ejequtarlo sin otro motibo que la falta de tienpo para la espedisión»»33.

Aunque el conde de Pinos Puente no había desempeñado previamente labores diplomáticas, se había hecho con informaciones útiles para sobrellevar la misión.

29. HHStA, Staatenabteilungen. Portugal, Karton 6. Carta del conde de Pinos Puente al conde Sinzendorf, Lisboa, 4 de enero de 1724. HHStA, Staatenabteilungen. Portugal, Karton 12. Carta del conde de Pinos Puente al conde Sinzendorf, Lisboa, 11 de enero de 1724.

30. Para las informaciones del cónsul imperial en torno a la conformación de la Companhia, véase HHStA, Staatenabteilungen. Portugal, Karton 6. Cartas de Giuseppe Zignoni a Carlos VI, Lisboa, 11 de enero, 1 de febrero, 25 de abril y 13 de junio de 1724 .

31. Gazeta de Lisboa Occidental, $n^{\circ}$ 3, 1724: s. p. Avisos de Lisboa, 20 de enero de 1724. Sobre la Compañía de Corisco en la triangulación atlántica del tráfico de esclavos setecentista, vid. SILVEIRA, 1949.

32. HHStA, Staatenabteilungen. Portugal, Karton 12. Carta del conde de Pinos Puente al conde Sinzendorf, Lisboa, 11 de enero de 1724.

33. Ibidem. 
Las prácticas de otros representantes de príncipes extranjeros en Lisboa le servían de espejo para tratar de implementar su comisión. Casos precedentes como los de cierto embajador francés radicado en la urbe durante años y que «jamás pudo concluir ningún negosio, i fue el prinsipal que solisitó el de un tratado de comersio entre las Dos Coronas», no parecían un buen acicate para soslayar el fracaso que parecía cernirse sobre el conde ${ }^{34}$. Por ello, pasados cuatro meses desde su arribo, comenzó a solicitar su restitución a Viena.

Junto a estos motivos directos, el deseo de retorno también parecía provenir de la imposibilidad de don Juan Jacinto para sustentarse con decoro en la corte lusa y mantener un alto grado de representatividad pública. Como nuevo polo de referencia de los intereses habsbúrgicos en la península Ibérica, el conde articuló en su residencia una extensa red de confidentes y amistades que le permitiesen proyectar la imagen vívida de su soberano entre la comunidad española expatriada. Así, se tiene constancia de haber amparado a sujetos como el togado Mateo Ibáñez de Segovia y Mendoza, hijo del difunto marqués de Mondéjar y ex-consejero de Órdenes y de Indias, o el militar Joseph de Peralta Manuel, que había servido en el regimiento de Granada bajo sus órdenes y que, aprisionado temporalmente en Ceuta tras la capitulación de Barcelona en I7I4, pasó a Lisboa para formar parte de la familia aristocrática del diplomático imperial ${ }^{35}$. Asimismo, el conde de Pinos Puente no rechazó su participación en los actos palatinos en los que era imprescindible la presencia de un ministro cesáreo. El 30 de enero asistió al besamanos de la infanta Francisca Josefa de Braganza, la hermana menor del monarca, y celebró «hum magnifico jantar» a los fidalgos portugueses y a los oficiales reales y representantes de otras potencias europeas. El acto, publicitado por la Gazeta de Lisboa Occidental, también fue recordado por el marqués de Angeja. Como asistente al banquete, el aristócrata elogió la mesa «muy chea de iguarias» y de variados vinos con los que Pinos Puente agasajó a sus comensales ${ }^{36}$. No parecía frívolo el dispendio que el diplomático hiciera en la fiesta con que celebrase a la infanta. El bloqueo práctico de su comisión negociadora podía romperse con un acto de tal envergadura en el que don Juan Jacinto se mostró como un caballero «muy capaz e de muito bom modo e cortezania». Idéntica consideración tuvo Angeja semanas más tarde, cuando volvió a anotar en su correspondencia el convite que hiciera el enviado del emperador con motivo del cumpleaños del infante Antonio Francisco de Braganza, otro de los hermanos del rey Juan V. En esta ocasión, la fiesta se vio opacada por la ausencia de numerosos fidalgos invitados, dado que se celebraba en paralelo una sesión del Conselho da Fazenda y se tenía noticia cierta de la enfermedad terminal del conde de Ribeira. Pese a todo, el marqués volvió a trazar la imagen positiva del diplomático y sus prendas personales:

34. Ibidem.

35. Los siguientes gozan diario de capitán que es de 15 florines, Viena, c. 1725, cfr. AlCOBERRO, 2002. AGS, Estado, legajo 6432. Carta del marqués Domenico Capecelatro al marqués de La Paz, Lisboa, 8 de octubre de 1726.

36. Carta del marqués de Angeja a Marco António de Azevedo Coutinho, Lisboa, 31 de enero de 1724, cfr. AzEVEDO, 1918: 1013. Gazeta de Lisboa Occidental, n 5, 1724: s. p. Avisos de Lisboa, 3 de febrero de 1724. 
«O conde de Pinos sim hé muy bom cavalhero, e faz muy boa figura nesta Corte no bom trato de toda a nobreza della, o que contribue muito para se conseguir o meyo de reprezentante sem charater ${ }^{37}$.

El status jurídico de Juan Jacinto Vázquez de Vargas como enviado extraordinario traspasaba, con actos oficiosos tanto en negociados políticos como en celebraciones festivas, el encorsetado rol de los embajadores extraordinarios u ordinarios de las testas coronadas ${ }^{38}$. Sin necesidad de realizar una costosa entrada pública, Pinos Puente destinaría la exigua financiación de su comisión a tales acontecimientos sociales que reforzaban su papel de emisario de Carlos Vl. Además, el conde fue comisionado para trasladar a sus correspondientes lisboetas otros asuntos de no menos calado en el tablero político internacional. Ejemplo de ello fue la entrevista que tendría a finales de marzo con el secretario Mendonça en torno a las noticias sobre la muerte del papa Inocencio XIII ${ }^{39}$. La voluntad del césar Carlos pasaba por insinuar a los cardenales portugueses que marcharan a Roma con motivo del cónclave la colaboración con los imperiales en pro del nombramiento de un nuevo pontífice afín a ambas monarquías. Mientras que la posibilidad de que Nuno da Cunha Ataíde se desplazara a la corte papal era inviable por sus achaques y enfermedades, sí parecía factible que José Pereira de Lacerda pudiese acudir a la elección y, allí, secundara a sus homólogos procesáreos. Menos posibilidades de éxito tendría una rápida resolución de los otros dos asuntos que llevaba tiempo tratando con los hombres de Juan V: la finalización del tratado de comercio y el particular del infante Manuel de Braganza. Pese al semestre que el conde llevaba tratando de alcanzar «un faborable ésito» en este último punto, solo podía esperar a que la Providencia divina coadyuvaría a obtener el perdón del monarca para su díscolo hermano.

Las negociaciones del conde de Pinos Puente en Lisboa prosiguieron en inercia durante el invierno y la primavera de i724. La dilatación de una resolución favorable para todos sus encargos hacía insoportable la misión diplomática. Poco acostumbrado a este tipo de servicio político y, frente a otros homólogos foráneos, falto de recursos económicos que le permitiesen soportar los enormes costes de representación, la espera de una feliz nueva de Viena, el inminente nacimiento de un nuevo descendiente para la pareja imperial, alteró la cotidianeidad del diplomático. A comienzos del año don Juan Jacinto se había felicitado con Sinzendorf por el embarazo de la emperatriz Isabel Cristina de Braunschweig-Wolfenbüttel, deseando el nacimiento de un varón que sucediera a Carlos VI. De hecho, el conde afirmó sin ambages a su corresponsal

37. Carta del marqués de Angeja a Marco António de Azevedo Coutinho, Lisboa, 14 de marzo de 1724, cfr. AZEVEDO, 1918: 1017.

38. Para una revisión crítica en torno a la evolución del status de los diplomáticos y de su cultura política durante la Edad Moderna, vid. Frigo, 2008; Bravo Lozano y Quirós Rosado, 2018; Bravo Lozano y Álvarez-OSSORIO AlvarIÑO, 2021.

39. HHStA, Staatenabteilungen. Portugal, Karton 12. Carta del conde de Pinos Puente al conde Sinzendorf, Lisboa, 25 de marzo de 1724 . 
«que muchos pueblos de España lo desían como nosotros, y asen rogatibas a este fin como pueden exequtarlo en Austria, porque la opresión en que se allan aquellos basallos les ase acordarse más que nunca de el dominio del Enperador nuestro señor» ${ }^{40}$.

Meses más tarde, ante la proximidad del parto de la emperatriz, los ánimos parecían acordes a sus deseos iniciales, detallando al canciller cesáreo la antelación con que preparaba las libreas de gala, carroza «i lo demás corespondiente» para acudir al Paço da Ribeira a llevar la noticia del nacimiento a Juan V. Cual reputado anfitrión de la fidalguia y el ministerio locales, Pinos Puente arriesgaría su cada vez más escaso capital en esta nueva publicidad diplomática para la Casa de Austria. Contando con el soporte de su suegro, el marqués de Rialp, y la mediación del conde Sinzendorf, el granadino se había garantizado una doble vía para asegurarse el apoyo necesario con que mantener sin mácula su reputación como fiel servidor del emperador, a la par que estas prendas le facilitarían un premio consecuente. Más que dignidades honoríficas, Pinos Puente quería mejorar su subsistencia en la corte de Lisboa. Con los doce mil florines anuales con que se financiaba su misión «no se puede aser un biage, el más largo de Europa, poner una casa de pie y mantenerse con la desensia que coresponde i la que aquí me an querido dar por quien me invía», reconocía don Juan Jacinto ${ }^{41}$.

Pese a todos sus desvelos, la ansiada ayuda pecuniaria no llegó desde Viena, ni tampoco se fue dilucidando el tratado de comercio luso-imperial. Los avisos impresos de Amsterdam, Luxemburgo y Foligno dieron pábulo a las noticias que situaban al conde de Pinos Puente de retorno inmediato a la corte de Carlos VI logrando -o no- sellar su comisión ${ }^{42}$. Sin embargo, la ambigüedad de tales referencias distaba de la realidad cotidiana del granadino. El 25 de abril remitió sendas notificaciones a Rialp y Sinzendorf con las novedades de su negociado mercantil. La primera consecución fue el envío de una orden para el virrey de la India para recibir a los navíos de la Compañía de Ostende en los diferentes puertos dependientes de Goa. El éxito de la solicitud situaba a los barcos flamencos en una posición preeminente en el comercio índico respecto al trato dado a franceses, británicos y neerlandeses. Frente a este pequeño triunfo, y pese a las buenas noticias dadas por el secretario Mendonça, el tratado de comercio seguía resistiéndose a su conclusión, si bien tras una consulta favorable de la junta ad hoc reunida el I7 de abril se fiaba el resto a la resolución de Juan $V$ «para si a de entrar, o no, algún ministro más que él a tratar» con Pinos Puente ${ }^{43}$.

40. HHStA, Staatenabteilungen. Portugal, Karton 6. Carta del conde de Pinos Puente al conde Sinzendorf, Lisboa, 4 de enero de 1724.

41. HHStA, Staatenabteilungen. Portugal, Karton 12. Carta del conde de Pinos Puente al conde Sinzendorf, Lisboa, 25 de marzo de 1724.

42. Lettres historiques, tomo LXV, 1724: 439. Avisos de Lisboa, abril de 1724. La clef du cabinet des princes de l'Europe, tomo XL, 1724: 325. Avisos de Lisboa, mayo de 1724. Foglio di Foligno, n² 20, 1724: s. p. Avisos de Viena, 6 de mayo de 1724.

43. HHStA, Staatenabteilungen. Portugal, Karton 12. Carta del conde de Pinos Puente al conde Sinzendorf, Lisboa, 25 de abril de 1724 . 
El primer éxito del conde no alejaba la sombra de un potencial fracaso a medio plazo. Las dificultades financieras del enviado extraordinario se acrecentaban día a día y podían, incluso, llegar a tal punto que «en el caso de benirme la horden para retirarme, yo no podré exequtarla sin los medios para pagar lo que aquí debo» ${ }^{4}$. Las deudas acumuladas parecían lesionar su representación diplomática, por lo que trató de dinamizar la resolución del tratado. A lo largo de las siguientes semanas cruzó con el secretario de Estado luso sus pareceres sobre este tenor. Comenzado mayo, don Juan Jacinto logró de Mendonça la entrega de los puntos sobre los que se negociaría firmemente el acuerdo mercantil y que, en paralelo, fueron tanto enviados al marqués de Rialp como debatidos con los sujetos prácticos en el comercio ultramarino de la monarquía habsbúrgica con Portugal: el cónsul Giuseppe Zignoni, el agente Pau Martí, Enea Barbarolli y «el director de la Conpañía, el señor Raisfelt» ${ }^{45}$.

En conexión privilegiada con Rialp, Pinos Puente prosiguió durante todo el mes remitiendo noticias en cifra a Viena, a la par que se preparó para poner en marcha la notificación oficial del alumbramiento de la archiduquesa María Amalia de Habsburgo. Dado lo avanzado de los preparativos realizados durante los meses precedentes, solo le era preciso conocer el modus operandi de la audiencia con Juan V y su esposa María Ana, tíos de la criatura. Dicho acto sería «ýnterin que se exequta con la formalidad regular lo que Sus Magestades estimaren» y mientras no llegase a Lisboa el emisario remitido por Carlos VI, el italiano Michele Strozzi. En todo caso, conocedor de las ambigüedades bragancistas, don Juan Jacinto afirmaría que «yo espero ber si la corte pone luminarias para aconpañar con las mías; y en el caso de no ponerlas, lo exequtaré yo, $\mathrm{u}$ antes u después de llegar Estrosi con la notisia formal» ${ }^{4}$.

Mientras se dilataban los debates sobre las galas de corte, Pinos Puente prosiguió relatando a sus corresponsales Rialp y Sinzendorf los pequeños avances en la materia mercantil, deseoso de recibir la orden de retirarse a Viena «en el caso que prebengo en mi sifra, u en el que se me hordene». La justificación de sus actos ya era conocida por el ministerio cesáreo, «pero como el suseso no coresponde asta aora, es indispensable la conformidad después de aber exequtado quanto a paresido regular» ${ }^{47}$. El tratado de comercio entre Juan V y Carlos VI dependía del papel ofrecido por el diplomático a la propuesta de máximos portuguesa, que glosaba el proyecto del mencionado Pau Martí, comerciante y armador catalán que se había distinguido en la causa habsbúrgica durante la guerra de Sucesión y que, desde i7i8, ocupaba la agencia cesárea en Lisboa tras el deceso de su hermano Joan ${ }^{48}$.

44. Ibidem.

45. HHStA, Staatenabteilungen. Portugal, Karton 12. Carta del conde de Pinos Puente al conde Sinzendorf, Lisboa, 9 de mayo de 1724.

46. HHStA, Staatenabteilungen. Portugal, Karton 12. Carta del conde de Pinos Puente al conde Sinzendorf, Lisboa, 16 de mayo de 1724.

47. HHStA, Staatenabteilungen. Portugal, Karton 12. Carta del conde de Pinos Puente al conde Sinzendorf, Lisboa, 23 de mayo de 1724.

48. HHStA, Staatenabteilungen. Portugal, Karton 6. Relación o apuntamientos que haze don Pablo Martín, agente por Su Magestad Cezárea y Cathólica en la corte de Lisboa y reyno de Portugal (...), Sin lugar, ni fecha (Lisboa, 1724). 
Las expectativas dadas por Diogo de Mendonça Corte Real sobre la consecución del acuerdo alimentaron las esperanzas del conde de Pinos Puente y del entourage imperial de Lisboa de aumentar los privilegios contenidos en el primer borrador remitido al secretario Rialp a comienzos de mayo, si bien se tenía por cierto que

«nunca consederán el todo de lo que les pedimos, parte por los reselos con que biben de los selos que este tratado puede ocasionar a las Potensias Marítimas, y parte por querer el Rei contenporisar con las Coronas de España y Fransia, pues abiendo deseado estas desde la conclusión de la pas [de Utrecht] el efectuar un tratado de comersio, no lo an consegido, ni con las más bibas instansias de sus enbagadores, por quias rasones políticas creo se embarasan acordar lo que la rasón prudente aconseja»49.

Una inesperada ayuda para la consecución del proyecto comercial podía provenir, según el conde, del mejoramiento de la situación política en Viena del infante Manuel de Braganza, nuevo gobernador de Austria Interior. Sin embargo, el diplomático dudaba de que un factor colateral que tocase la compleja relación entre Juan $\mathrm{V}$ y su hermano ausente pudiese facilitar el éxito de su misión. La posible negociación de un matrimonio doble entre las cortes de los Braganza y los Borbón madrileños - del cual Pinos Puente había buscado «el más bibo medio de indagarlo»- subyacía en tales dudas y reforzaba al diplomático en la convicción de la tibieza del monarca luso. En todo caso, el enviado imperial acordó con sus interlocutores vieneses su estancia en Lisboa hasta que se conociese «el efeto que causa la interposisión de el nuebo papa, pues en este ínterin se berá el ésito de el tratado de el comersio, con lo que no me quedará que esperar, u con la consequsión, u con el desengaño ${ }^{50}$. Triunfo o fracaso se hallaban ya, por tanto, en el horizonte de la comisión portuguesa de don Juan Jacinto. Una indefinición similar a la suerte de los comerciantes de la Compañía Oriental de Trieste, pues mientras su nave San Leopoldo cargaba ricos productos ultramarinos -y unos loros que regalaría el diplomático granadino a la esposa del conde Sinzendorf, Rosina Katharina von Waldstein-, sus directores vendieron el barco Primogenito a la Companhia de África, posiblemente como medio para garantizar la colaboración atlántica entre ambas sociedades ${ }^{51}$.

El primero de junio de 1724 alcanzó la rada de Lisboa el paquebote británico que trasladaba al ayuda de cámara imperial Michele Strozzi con la noticia oficial del nacimiento de la archiduquesa María Amalia. Don Michele fue rápidamente presentado a la audiencia de la reina María Ana de Habsburgo, a quien entregó las cartas cesáreas, mientras que las dirigidas al rey Juan $V$ se remitieron al secretario Mendonça para que las presentase al monarca ausente. Paradójicamente,

49. HHStA, Staatenabteilungen. Portugal, Karton 12. Carta del conde de Pinos Puente al conde Sinzendorf, Lisboa, 30 de mayo de 1724.

50. Ibidem.

51. HHStA, Staatenabteilungen. Portugal, Karton 6. Carta de Giuseppe Zignoni a Carlos VI, Lisboa, 13 de junio de 1724. HHStA, Staatenabteilungen. Portugal, Karton 12. Carta del conde de Pinos Puente al conde Sinzendorf, Lisboa, 7 de agosto de 1724. 
solo el cónsul Zignoni festejó la nueva, con tres noches de luminarias ${ }^{52}$. No se tiene constancia que Pinos Puente, inmerso en el laberinto del tratado de comercio, iluminase su residencia, ni tampoco solemnizara con un banquete el cumpleaños del príncipe de Brasil, José de Braganza, como sí hiciese meses atrás con los infantes. Las noticias que el enviado extraordinario diese a Sinzendorf a fines de junio le representaban preparando para su marcha, pues «sobre lo que ai tan poco qué esperar, que solo pienso en mi retorno, si no me lo enbarasa alguna horden superior» ${ }^{53}$.

El inicio del verano de 1724 se presentaba exasperante para el andaluz, máxime tras la muerte del cónsul Giuseppe Zignoni por un ataque de apoplejía. Este italiano, que durante años había servido fielmente a Carlos Vl, dejaba en Lisboa hijos y una mujer que no dudó en requerir el apoyo de Pinos Puente para lograr la protección cesárea. Mediando por la familia del difunto, el conde escribió al conde Sinzendorf, a la par que recogía los papeles del finado y mandaba a Viena sendas cartas para el canciller y el secretario del Despacho Universal presentando los servicios del agente catalán Pau Martí como potencial cónsul en Lisboa ${ }^{54}$. Mientras tanto, la consecución del tratado de comercio no parecía finalizarse, de tal manera que corrieron voces de la inminente marcha del descontento enviado extraordinario en un barco británico hacia Génova y Viena ${ }^{55}$.

Pese a los rumores, don Juan Jacinto persistió en sus negocios durante todo el estío, manteniendo informados a sus corresponsales de todos sus pasos. Uno de sus objetivos fue la entrega de una copia de las órdenes que, meses atrás, Juan V habría remitido al virrey de la India portuguesa a favor de la Compañía de Ostende, que solo pudo ver en el libro copiador de los despachos secretos. Su intento fracasó, pero sus interlocutores «tomaron el medio término de degarme leer» el volumen, a la misma vez que el diplomático lograba incluir en el borrador del tratado un artículo sobre la protección de los navíos imperiales «que nos dega bien a el qubierto en esta parte» ${ }^{56}$. Así, a comienzos de agosto, el conde mantuvo una nueva conferencia con Diogo de Mendonça Corte Real para terminar de reglar el acuerdo que debía firmar el monarca luso. La corporación que quedaría más beneficiada no era la Compañía triestina, sino la de Ostende, que veía amparado el arribo de sus naves en los puertos portugueses

«aunque no abiertamente, pero de forma que basta para la seguridad de nuestro comersio en aquellas partes; y no es creíble el trabago que con espesialidad me a costado este artíqulo i otros de el tratado» ${ }^{57}$. de 1724

52. HHStA, Staatenabteilungen. Portugal, Karton 6. Carta de Giuseppe Zignoni a Carlos VI, Lisboa, 6 de junio

53. HHStA, Staatenabteilungen. Portugal, Karton 12. Carta del conde de Pinos Puente al conde Sinzendorf, Lisboa, 20 de junio de 1724.

54. HHStA, Staatenabteilungen. Portugal, Karton 12. Carta del conde de Pinos Puente al conde Sinzendorf, Lisboa, 20 de junio de 1724, y carta de Pau Martí al conde de Sinzendorf, Lisboa, 27 de junio de 1724.

55. Foglio di Foligno, n 35 , 1724: s. p. Avisos de Lisboa, 9 de julio de 1724. Regesto de carta de Thomas Burnett al duque de Newcastle, Lisboa, 9 de julio de 1724, cfr. Descriptive list, 1979: 11.

56. HHStA, Staatenabteilungen. Portugal, Karton 12. Carta del conde de Pinos Puente al conde Sinzendorf, Lisboa, 1 de agosto de 1724.

57. HHStA, Staatenabteilungen. Portugal, Karton 12. Carta del conde de Pinos Puente al conde Sinzendorf, Lisboa, 7 de agosto de 1724. 
La euforia del conde de Pinos Puente, tras meses de arduas negociaciones, era tal que llegó a afirmar a sus corresponsales cómo los hombres inteligentes del comercio lisboeta, caso de Martí y los agentes de la Compañía Oriental, reconocieron el éxito de la causa de Carlos VI frente a otros monarcas enemigos, principalmente Francia y la España de Felipe $V$, a decir de la infructuosa negociación del marqués Domenico Capecelatro para lograr un tratado similar desde la firma de la paz en I715. Pese a todo, los temores del enviado extraordinario a que no se lograse efectuar el negociado no provenía de las Dos Coronas borbónicas, sino de la emulación de Gran Bretaña y las Provincias a la introducción de los vasallos del emperador en Flandes, Italia y el Erblande austriaco en las rutas globales del comercio. Para el diplomático, «nosotros emos tenido que benser la oposisión que an echo las Potensias Marítimas», a la vez que lograba sortear «la natural que esta corte tiene para no concluir nada y ganar tienpo, aún en lo que más les inporta» o los intentos del secretario Mendonça para asimilar la causa cesárea a los tratos con la España borbónica. En este sentido, el celo político del conde no dejaba lugar a medianías. «[E]l enperador, mi amo, solo era egenplar de sí mesmo», llegaría a responder el granadino al secretario luso ${ }^{58}$.

La evolución positiva del soporte de Portugal a los intereses ultramarinos de la monarquía habsbúrgica, al menos para la protección de sus feitorias a los navíos provenientes de los Países Bajos austriacos, constituía un pequeño triunfo, pero ocultaba el fracaso en la obtención de mayores réditos mercantilistas para las dos compañías privilegiadas por el césar Carlos. Dado que los negociados principales para los que fue remitido el conde de Pinos Puente no parecían alcanzar el resultado esperado un año atrás, el aristócrata decidió detenerse algunas semanas más en Lisboa «por apurar la poca esperansa que ai sobre esta dependiensia»59. Durante el tiempo añadido de su misión es factible que don Juan Jacinto ordenase los preparativos de su partida, la liquidación de sus deudas y, para entonces, requiriera de los monarcas la obtención de los retratos del príncipe del Brasil y la infanta María de Braganza de mano del pintor turinés Giorgio Domenico Duprà, como un regalo para entregar a la pareja imperial ${ }^{60}$. Por último, negoció con los ministros reales la audiencia de despedida con Juan $\mathrm{V}$, la cual, a decir de las informaciones transmitidas por el cónsul británico Thomas Burnett, tuvo lugar a comienzos de septiembre ${ }^{61}$. El objetivo decisivo del emperador de convertir a Portugal en una pieza esencial de sus proyectos ultramarinos había fracasado, aunque, a cambio, se habría conseguido que los barcos con pabellón cesáreo accediesen libremente a los puertos marítimos lusos, tanto en la deseada India como en sus escalas africanas, brasileñas y europeas.

58. Ibidem. Sobre las fracasadas negociaciones comerciales del napolitano Capecelatro tras la reactivación de lazos diplomáticos entre Lisboa y Madrid, vid. Pradells NAdAL, 1992, pp. 348-350; García ArenAs, 2015, pp. 95-97.

59. HHStA, Staatenabteilungen. Portugal, Karton 12. Carta del conde de Pinos Puente al conde Sinzendorf, Lisboa, 7 de agosto de 1724 .

6o. AHN, Estado, legajo 2656. Carta del marqués Domenico Capecelatro al marqués de Grimaldo, Lisboa, 1 de mayo de 1725, cfr. BORGES, 2016: 323. RIBEIRO DE FARIA, 2012: 77, n. 115

61. Regesto de carta de Thomas Burnett al duque de Newcastle, Lisboa, 2 de septiembre de 1724, cfr. Descriptive list, 1979: 12 


\section{UN EPÍLOGO ENTRE ROMA, VIENA Y, DE NUEVO, LISBOA}

La misión diplomática de Juan Jacinto Vázquez de Vargas en Lisboa terminó el 7 de octubre de I724, cuando se embarcó para Italia en una escuadra de la Orden de Malta que había recalado en la corte lusa para recoger al sobrino del gran maestre António Manoel de Vilhena ${ }^{62}$. El 8 de noviembre, tras mudar su nave a un navío británico, recaló en Nápoles, desde donde aguardó las órdenes que le haría llegar Carlos Vl. Allí, en la urbe partenopea, aprovechó la posta para escribir a Viena, en particular al príncipe Eugenio de Saboya para darle aviso de no haber sido posible «en la corte de Lisboa concluir el tratado de comersio» ${ }^{63}$.

Su marcha hacia la capital imperial se ralentizó no por una censura del soberano o del ministerio ante la frustración del negociado ultramarino a cargo del conde, sino para aprovechar su capacidad diplomática en otros asuntos de envergadura política. Pinos Puente recibió el mandato de dirigirse a Roma para pasar allí el resto del otoño e invierno ${ }^{64}$. Quien le hospedaría era el cardenal Álvaro Cienfuegos, eminente jesuita que se había radicado desde 1702 en Lisboa en el séquito del almirante de Castilla y que -como se indicó con anterioridad- sirvió de medianero y plenipotenciario de Carlos III en plena guerra de Sucesión ${ }^{65}$. Bajo la cobertura del purpurado asturiano, el conde gestionó de manera informal la resolución de un affaire diplomático que había enrarecido las relaciones entre Viena y Roma: la devolución de la plaza fuerte de Comacchio. Conquistada por el emperador José I en I708, el dominio de la estratégica plaza adriática generó abiertas tensiones durante el pontificado de Clemente $\mathrm{XI}^{66}$. Aunque algunos cronistas coetáneos como Francesco Maria Ottieri afirmaban que los motivos de la potencial evacuación se debían al «scrupolo e timore che Iddio per questa cagione non gli avesse dato, e non gli desse figlj maschi» al emperador ${ }^{67}$, solo en vísperas del acercamiento entre Felipe V y Carlos VI mediante la labor secreta del barón de Ripperda la resolución el conflicto parecía abocarse a su fin. Por ello, el conde de Pinos Puente terminó recibiendo la comisión oficial de entrevistarse con el papa Benedicto XIII y acordar la salida de las tropas imperiales del presidio ${ }^{68}$.

Tras ejecutar dicho encargo entre enero y febrero de I725, Juan Jacinto Vázquez de Vargas pudo marchar a su residencia vienesa. Ausente de ella desde hacía más de año y medio, el granadino retornaba con su fama intacta. La obtención de ciertos privilegios mercantiles para las compañías de Ostende y Trieste en la corte de Lisboa y la firma de un acuerdo que mejoraba sustancialmente el crédito político cesáreo

62. The London Gazette, n 6311, 1724: s. p. Avisos de Lisboa, 7 de octubre de 1724.

63. Gazeta de Lisboa Occidental, n² 2, 1725: s. p. Avisos de Nápoles, 14 de noviembre de 1724. HHStA, Große Korrespondenz, Karton 102b. Carta del conde de Pinos Puente al príncipe Eugenio de Saboya, Nápoles, 10 de noviembre de 1724 .

64. La clef du cabinet des princes de l'Europe, tomo XLIII, 1725: 111. Avisos de Roma, noviembre de 1724. Foglio di Foligno, $n^{\circ}$ 49, 1724: s. p. Avisos de Roma, 2 de diciembre de 1724.

65. En Lisboa, el jesuita se convirtió en un importante nodo en la circulación financiera entre Londres y la corte habsbúrgica de Barcelona. GRAHAM, 2014.

66. Sobre la guerra de Comacchio (1708), vid. Martín MARCos, 2011: 128-138.

67. OtTIERI, 1757: 376.

68. Gazeta de Lisboa Occidental, n 14, 1725: s. p. Avisos de Roma, 24 de febrero de 1725 
ante la Santa Sede constituirían dos jalones en el cursus honorum del militar reconvertido en diplomático. Para Carlos VI y su corte se habían logrado dos éxitos pírricos para su búsqueda de nuevos equilibrios que sostuviesen la gravedad del imperium habsbúrgico. La consecución de la paz con la España borbónica merced al tratado de Viena, firmado el 30 de abril de I725, contribuiría en ello y, en particular, en el reforzamiento del proyectismo mercantil de los vasallos del emperador ${ }^{6}$. El apoyo que estos recibirían del rey de España y del ministerio madrileño forzaría a las demás potencias europeas a replantear su posición ante el avance comercial vienés. De otra manera no podría comprenderse cómo, tras las dilaciones que el conde de Pinos Puente viviese durante su estancia lisboeta, Juan V instruyera para su nuevo embajador a la corte imperial conminándole a encontrar puntos sobre los que articular una liga con un marcado carácter ultramarino y que facilitase - por la mediación de Carlos VI- el reconocimiento de Felipe V a la posesión lusa de Colônia do Sacramento:

«E para que que a Liga não fique só nos termos de hua comum amizade, e reciproca correspondencia tambem por artigo separado, e secreto se pode substituir de huma, e outra parte a falta de socorros com outros interesses, os quais poderão ser da minha parte o Tratado de Comércio, que o Imperador há tanto tempo deseja que se ajuste entre a Duas Coroas o qual vós fareis sempre valer muito, ponderando os graves inconvenientes que dele resultam a meus vassalos, como bem mostrou a dificuldade e embaraços que sobre esta matéria achou o conde de Pinos quando veio a estas negociações, da qual ao diante vos mando instruir; e pela parte do Imperador contribuirá ele com a interposição dos seus mais eficazes ofícios para conseguir que a corte de Madrid, reconhecendo a clara justiça que me assiste para o inteiro cumprimento dos tratados, me não inquiete na plena posse do amplo território que com a Colónia do Sacramento me cedeu, como vós sabeis, transigindo El-Rei» ${ }^{70}$.

Do ut des, como no podía ser de otra manera, actuaba como la máxima rectora para la búsqueda de intereses comunes que facilitaran un acuerdo entre dos de los príncipes más representativos de la Europa católica y, sobre todo, de dos partícipes de una tercera ratio que regularía la vida de sus súbditos más allá de la «religión» o el «estado»: la razón del comercio.

69. Mur RaureLL, 2011

70. Instrucciones de Juan V a João Gomes da Silva, conde de Tarouca, Lisboa, 30 de agosto de 1725, cfr. BRAZÃo, 1980: $95-96$ 


\section{FUENTES IMPRESAS Y BIBLIOGRAFÍA}

Alcoberro, Agustì, L'exili austriacista (I7I3-I747), vol. Il, Barcelona, Fundació Noguera, 2002.

Alves Miranda, João Manuel da Silva, As relações diplomáticas entre Portugal e a Rússia na época de Pedro, o Grande (I7oo-I725), Lisboa, Fundação Calouste Gulbenkian. FCT. Ministério da Ciência e da Tecnologia, 2002.

AndreOzzI, Daniele, «La gloria di un dilatato commercio. L'intrico delle politiche e lo sviluppo di Trieste nell'Adriatico centro settentrionale (I700-I730)», Mélanges de l'École française de Rome, I27/I (2015).

Azevedo, Pedro de (ed.), «Cartas do marquez de Angeja a Marco António de Azevedo Coutinho (I72I-I725)», Boletim da Segunda Classe da Academia das Ciências de Lisboa, II (I9I8).

BıcAlho, Maria Fernanda y Costa, André da Silva, «O Conselho Ultramarino e a emergência do Secretário de Estado na comunicação política entre reino e conquistas», en João Fragoso y Nuno Gonçalo Monteiro (eds.), Um Reino e suas Repúblicas no Atlântico, Rio de Janeiro, Civilização Brasileira, 20I7: I37-I58.

Borges, Sónia, Duas cortes, um modelo: o cerimonial diplomático nas relações luso-espanholas (I7I5-I750). Apéndice documental. Tesis doctoral inédita, Lisboa, Universidade de Lisboa, 2016.

Bravo lozano, Cristina y Álvarez-Ossorio Alvariño, Antonio (eds.), Los embajadores. Representantes de la soberanía, garantes del equilibrio (1659-I748), Madrid, Marcial Pons Historia, 202I.

Bravo Lozano, Cristina y QuiRós Rosado, Roberto (eds.), Rappresentare a Corte. Reti diplomatiche e cerimoniali di Antico Regime. Cheiron. Materiali e strumenti di aggiornamento, I (20I8).

BrAZÃo, Eduardo, A diplomacia portuguesa nos séculos XVII e XVIII, tomo I, Lisboa, Editorial Resistência, I980.

CARDucci, Giosuè (ed.), Lettere disperse e inedite di Pietro Metastasio, vol. I, Bolonia, Nicola Zanichelli, I883.

Correia, Maria Alcina Ribeiro, Sebastião José de Carvalho e Mello na corte de Viena de Áustria. Elementos para o estudo da sua vida pública, I744-I749, Lisboa, Instituto de Alta Cultura. Centro de Estudos Históricos, I965.

Costa Trost, Margarita, Ramon Frederic Vilana-Perlas i Camarasa, marquès de Rialp, i el Regomir de Barcelona, Barcelona, Fundació Noguera, 2016.

Descriptive list of the State Papers Portugal, I66I-I780, in the Public Record Office, London, Lisboa-Londres, Academia das Ciências de Lisboa-British Academy-Public Record Office, I979.

Dhondt, Frederik, «La culture juridique pratique au Congrès de Cambrai (I722-I725)», Revue d'Histoire Diplomatique, I27 (2013): 27I-292.

DreIJER, Gijs, Bargaining for shelter. An entrepreneurial analysis of the Ostend Company, I7I4-I74O, tesis inédita de máster, Leiden, Leiden Universiteit, 2017.

FABER, Eva, «Il ruolo dell'Austria interiore nella politica commerciale di Carlo VI», Cheiron, 2I (I994): I6I-I86.

Foglio di Foligno, Foligno, per Feliciano e Filippo Campitelli stampatori vescovili, I723-I724. Frigo, Daniela, «Prudence and Experience: Ambassadors and Political Culture in Early Modern Italy», Journal of Medieval and Early Modern Studies, 38/I (2008): 15-34. 
García Arenas, Mar, «La situación de los comerciantes españoles en Lisboa desde la perspectiva de los diplomáticos de la Monarquía Hispánica destinados en Portugal en el Setecientos», AMMENTU. Bolletino Storico e Archivistico del Mediterraneo e delle Americhe, 7 (20I5): 9I-I03.

Gazeta de Lisboa Occidental, Lisboa, na officina de Pascoal da Sylva, I724-1725.

GraHAM, Aaron, «Public Service and Private Profit: British Fiscal-Military Entrepreneurship Overseas, I707-1712», en Jeff Fynn-Paul (ed.), War, Entrepreneurs, and the State in Europe and the Mediterranean, 1300-I800, Leiden-Boston, Brill, 2014: 87-IIO.

La clef du cabinet des princes de l'Europe, Luxemburgo, chez André Chevalier, imprimeur de Sa Majesté Imperiale \& Catholique, \& marchand libraire, I724-I725.

Le Mercure, París, chez Guillaume Cavelier, 1723.

León SAnz, Virginia, El Archiduque Carlos y los autracistas. Guerra de Sucesión y exilio, San Cugat del Vallés, Editorial Arpegio, 2014.

Lettres historiques, Amsterdam, chez la veuve de Jaq. Desbordes, I723-I724.

LuUCH, Ernest, L'alternativa catalana (I700-I7I4-I740). Ramon de Vilana Perlas i Juan Amor de Soria : teoria i acció austriacistes, Vic, Eumo Editorial, 2000.

Marina Barba, Jesús, Poder municipal y reforma en Granada durante el siglo XVIII, Granada, Universidad de Granada, I992.

Martín Marcos, David, El Papado y la Guerra de Sucesión española, Madrid, Marcial Pons Historia, 20II.

Martín Marcos, David, Península de recelos. Portugal y España, I668-I715, Madrid, Marcial Pons Historia-Instituto Universitario de Historia Simancas, 2014.

Martínez Fernández, Gabriel, De Ilurco a Pinos Puente. Poblamiento, economía y sociedad en un pueblo de la Vega de Granada, Granada, Diputación Provincial de Granada, I998.

Mur Raurell, Anna, Diplomacia secreta y paz. La correspondencia de los embajadores españoles en Viena, Juan Guillermo Ripperda y Luis Ripperda (I724-I727), Madrid, Ministerio de Asuntos Exteriores, 20II.

OтTIERI, Francesco Maria, Istoria delle guerre avvenute in Europa e particolarmente in Italia per la successione alla Monarchia delle Spagne dall'anno I696 all'anno I725, tomo IV, Roma, presso gli eredi di Giovanni Lorenzo Barbiellini, I757.

Pradells Nadal, Jesús, Diplomacia y Comercio. La expansión consular española en el siglo XVIII, Alicante, Universidad de Alicante-Instituto de Cultura «Juan Gil-Albert», I992.

Quirós Rosado, Roberto, «Proyectos militares y nuevos virreinatos en la guerra de Sucesión española: Galicia ante la monarquía de Carlos III de Austria», Tiempos Modernos. Revista Electrónica de Historia Moderna, 33 (2016): II2-I3I.

Quirós Rosado, Roberto, Monarquía de Oriente. La corte de Carlos III y el gobierno de Italia durante la guerra de Sucesión española, Madrid, Marcial Pons Historia, 2017.

RIBEIRO DE FARIA, Breno Marques, Retratos do poder: a pintura de retrato setecentista da família real portuguesa no Brasil. Disertación de Mestrado inédita, Campinas, Universidade Estadual de Campinas, 2012.

Silva, Francisco Xavier da, Elogio fúnebre, e histórico do muito alto, poderoso, augusto, pio, e fidelissimo rey de Portugal, e senhor dom João V, Lisboa, na Regia Officina Sylviana, e da Academia Real, I750.

Silveira, Luís, «Um episódio da história do comércio luso-brasílico: a fundação da Companhia da Ilha do Corisco», Instituto Histórico e Geográfico Brasileiro, 5 (I949): 517-529.

SoARes, Ernesto, O infante D. Manuel, I697-I766. Subsídios para a sua biografia, Lisboa, s. e., 1937 . 
Sotтo, Serafín María de (conde de Clonard), Historia orgánica de las armas de infantería y caballería españolas desde la creación del ejército permanente hasta el día, vol. IX, Madrid, Imprenta del Boletín de Jurisprudencia, 1856.

The London Gazette, Londres, printed by S. Buckley, I723-1724.

Wanner, Michal, «The Ostend Company as Phenomenon of International Politics in I722-I73I», Prague Papers on the History of International Relations, Io (2006): 29-63.

WANNER, Michal, «The establishment of the General company in Ostend in the context of the Habsburg maritime plan», Prague Papers on the History of International Relations, II (2007): 33-62. 


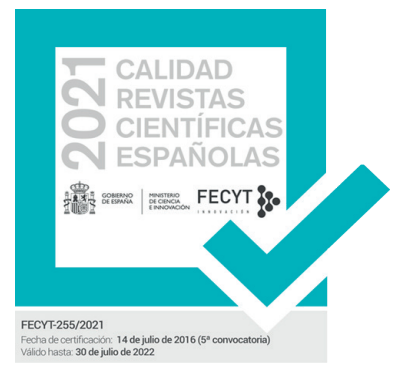

SERIE IV HISTORIA MODERNA

REVISTA DE LA FACULTAD DE GEOGRAFÍA E HISTORIA

AÑO 2021

ISSN: 1131-768X

E-ISSN 2340-1400

\section{4 \\ 西 ESPACIO, TIEMPO Y FORMA}

Monográfico - Special Issue: La política ultramarina de las monarquías ibéricas (circa 1700-1750): una historia de fracasos y éxitos relativos The Overseas Policy of the Iberian Monarchies (Circa 1700-1750): A History of Failures and Relative Successes

15 Roberto Quirós Rosado y MARIA FERnANDA BICALHO La política ultramarina de las monarquías ibéricas (circa 1700-1750): una historia de fracasos y éxitos relativos / The Overseas Policy of the Iberian Monarchies (Circa 1700-1750): A History of Failures and Relative Successes

\section{Guillaume Hanotin}

Defender negocios en tiempo de convulsión política: las elites mercantiles francesas durante la guerra de Sucesión española / Protecting Business in Time of Crisis: French Trademen during the War of Spanish Succession

\subsection{Maria Fernanda Bicalmo}

Ultramarino y el auge de los secretarios de Estado en Portugal durante la primera mitad del siglo XVIII / Sobre este modo de resolver e despachar os negócios. The decline of the Overseas Council and the Rise of the Secretaries of State in Portugal during the First Half of the $18^{\text {th }}$ Century

\section{9}

\section{VALENTINA FAVARò}

El fracaso de los proyectos de reforma en el virreinato peruano de principios

del siglo XVIII. Las propuestas de Carmine Nicola Caracciolo, príncipe de Santobuono the Eighteenth Century. The Proposals of Carmine Nicola Caracciolo, Prince of Santobuono

\section{7}

\section{ROBERTO QUIRÓS ROSADO}

Ecos de un mercantilismo truncado. El conde de Pinos Puente y la diplomacia comercial de Carlos VI en la corte de Lisboa (1723-1724) / Echoes of a Failed Mercantilism. The Count of Pinos Puente and the Commercial Diplomacy of Charles VI at the Court Of Lisbon (1723-1724)

\section{Junia Ferreira Furtado}

Portuguese America under Foreign Threat and the Creation of the Concept of uti possidetis in the First Half of the $18^{\text {th }}$ Century / La américa portuguesa bajo la amenaza exterior y la creación del concepto de uti possidetis en la primera mitad del siglo XVIII

\section{Miscelánea $\cdot$ Miscellany}

\section{José Antonio Mateos Royo}

con Cataluña / Trade Policy and Monetary Circulation in Aragon: Conflicts and Agreements with Catalonia (1535-1565)

\section{Fernando Altoé}

panegíricos atribuidos a la impresion. Un estudio de la trayectoria de dos the Trajectory of Two Panegyrics Attributed to João de Barros

\section{Francisco Velasco Hernández}

reino de Murcia (siglos XVI y XVII) / The Influence of the Berber Corsican on the Late Repopulation on the Coastal Area on the Kingdom of Murcia (XVI and XVII Centuries)

\section{José Antonio Martínez Martínez}

Criados, jornaleros y esclavos al servicio de la familia: la servidumbre de Serfdom of the Muñoz de Otálora in the $17^{\text {th }}$ Century

\section{Víctor Daniel Regalado González-Serna}

Benito de Medina a raíz de su ingreso en el cabildo catedral de Sevilla en 1669 / «Not a Single Good Portuguese». Accusations against Priest Alonso Benito de Medina when Entering the Cathedral Chapter of Seville in 1669

\section{José Herrera Reviriego}

organigrama comercial y militar de la Gober a tólo mitad del siglo XVII / "Only Time will Tell us»: The Role of Taiwan within the Commercial and Military Organization of the Philippine's Governoration during the First Half of the Seventeenth Century

\section{Manuel-Reyes García Hurtado}

de Rande, 1719-1733 / Vicissitudes of the Rescue Companies of the Sunken Ships in the Battle of Rande, 1719-1733

\subsection{Marcos de Miguel Muñoz}

Caballeros in 1769 


\section{4 ESPACIO, TIEMPO Y FORMA}

\section{Javier Tinoco Domínguez}

Tensiones sociopolíticas en el marco del catastro de Ensenada en Jerez de la Frontera: estudio de un conflicto institucional / Socio-Political Tensions within the Framework of Cadastre of Ensenada In Jerez de la Frontera: A Studying of an Institucional Conflict

\section{Pablo Fernández Albaladejo}

Fábulas de origen y gramática de nación en la España del siglo XVIII. A propósito de algunos trabajos de Francisco Martínez Marina / Origin's Fables and Grammar of Nation in the XVIII Century Spain. About some Works by Francisco Martínez Marina

\subsection{José María IÑURRITEgui Rodríguez}

Constitución increada: Francisco Martínez Marina y la crítica bíblica / Uncreated Constitution. Francisco Martínez Marina and Biblical Criticism

\subsection{David A. Abián Cubillo}

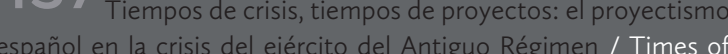
crisis, Times of Projects: The Spanish proyectismo during the Army's Crisis in the Ancient Regime

Taller de historiografía · Historiography Workshop

\section{Ensayos · Essays}

\subsection{ChrISTOPH ROSENMÜLLER}

«Tan peligrosas y feas conspiraciones»: la relación escrita por el embajador austriaco Christoph Migazzi en 1754 sobre la caída del marqués de la Ensenada / «Dangerous and Ugly Conspiracies». The Report of the Austrian Ambassador Christoph Migazzi on the Fall of the Marquis of la Ensenada in 1754

\subsection{Serge Gruzinskı}

Quelle histoire enseigner en 2021 ? / ¿Qué historia enseñar en 2021?

\subsection{Carlos Amate Pizarro}

Las relaciones hispano-chinas en el siglo XVI: síntesis e interpretación a la luz de la reciente historiografía / The Hispanic-chinese Relationship in the XVI Century: Synthesis and Interpretation in the Light of Recent Historiography

\section{Reseñas • Book Review}

521 Bolufer Peruga, Mónica, Arte y artificio de la vida en común. Los modelos de comportamiento y sus tensiones en el Siglo de las Luces, (Julio ArRoyo Vozmediano) 


\section{4 ESPACIO, TIEMPO Y FORMA}

525 Melón, Amando, Alejandro de Humboldt. Vida y obra (Carlos Martínez Shaw)

52 Commentary to Tatiana Seijas' review of The Atlantic World and the Manila Galleons: Circulation, Market, and Consumption of Asian Goods in the Spanish Empire (JosÉ LuIs GASCH TOMAS)

533 Braguier, Laurey, Servantes de dieu. Les beatas de la Couronne de Castille (1450-1600) (Manuela Águeda GARCÍA-GARRIDO)

539 Romeo, María CRuz; SAlomón, María Pilar; TABANERA, Nuria (eds.): Católicos, Reaccionarios y Nacionalistas. Política e identidad nacional en Europa y América Latina Contemporáneas (JAVIER M. Dos SANTOS)

54 Heredia López, Alfonso Jesús, El control de la corrupción en la Monarquía Hispánica. La Casa de la Contratación (1642-1660) (José Manuel Díaz Blanco)

17 Andújar Castillo, Francisco, El Atila de Madrid. La forja de un banquero en la crisis de la monarquía (1685-1715) (Aitor Díaz PAREdes)

551 Serrano Aviles, Javier y Mojarro, Jorge (eds.) Prada GonzALEZ, María (coord. de ilustraciones), En el archipiélago de la Especiería. España y Molucas en los siglos XVI y XVII (İ̃̃ıGo VALPUESTA VILLA)

555 Díaz Ceballos, Jorge, Poder compartido. Repúblicas urbanas, Monarquía y conversación en Castilla del Oro, 1508-1573 (JUAN SEbAstián Gómez GonZÁleZ)

51 Edelmayer, Friedrich, Massimiliano II, Filippo II I'Italia imperiale. II marchesato di Finale, i diritti imperiali e il «camino spagnolo» (RAFAEL VALLADARES)

56 Escribano-PÁEZ, José M., Juan Rena and the Frontiers of Spanish Empire, 1500-1540 (DAvid Martín Marcos)

56 ARnOLD, David, La Era de los Descubrimientos (1400-1600), Madrid, Alianza Editorial, 2021, 184 Pp., ISBN: 978-841362-172-2 (CARlos Amate Pizarro) 